\title{
We Are Not Alone in Trying to Be Alone
}

\author{
Patricia C. Lopes* \\ Schmid College of Science and Technology, Chapman University, Orange, CA, United States
}

Keywords: COVID-19, social behavior, sickness behavior, parasite avoidance, disgust avoidance, disease transmission

Certain diseases, like colds, tend not to stop us. A paracetamol here, an ibuprofen there, and we are on the go. That is, until we, as a species, are faced with a virus that not only spreads through social contact, but has an estimated reproductive number of 2 to 2.5 and potentially kills 3-4\% of those infected (WHO, 2020). To reduce transmission probability of COVID-19, governmental agencies around the world have recommended or enforced measures to decrease social contact; early evidence suggests these measures produce the intended effect (Kucharski et al., 2020).

\section{WOULD WE HUMANS TEND TO DO THIS NATURALLY?}

Interesting insights can be found from studying how other animal species change their behavior when infectious disease is present, and by considering the extent to which these changes are self-regulated or enforced by other individuals. Recently, a study by Stockmaier et al. (2020) suggested that vampire bats (Desmondus rotundus) decrease social contacts when exposed to an immune challenge, but in a non-random way. Contacts between mothers and their offspring are maintained regardless of either being immune challenged but contacts of immune challenged animals to non-close kin are decreased. In this instance, the behavior seems to be self-regulated. Wild mice (Mus domesticus) have also been found to cut ties to their social groups when feeling sick (Lopes et al., 2016), but in this case kinship does not appear to play a role (Lopes et al., 2018). The effects of sickness in reducing host social contacts tend to be so robust that, in laboratory rodent studies, a standard test to verify sickness symptoms quantifies the decrease in social exploration of juvenile conspecifics by the host (Dantzer, 2001). A group of animals that is particularly susceptible to socially transmitted parasites are social insects given the high density of individuals living together and, in many cases, the high degree of genetic similarity amongst them. Here too, it is found that pathogen-exposed individuals or even individuals dying from other, non-infectious, causes spend more time away from their colonies (Müller and Schmid-Hempel, 1993; Heinze and Walter, 2010; Bos et al., 2012; Stroeymeyt et al., 2018).

The vampire bat, rodent and social insect studies are examples of when the sick animals change their social behavior. But several studies have highlighted the ability for a number of different species to recognize disease cues and avoid animals displaying those cues. For instance, mandrills (Mandrillus sphinx) avoid both fecal material from and grooming of parasitized conspecifics (Poirotte et al., 2017). Female olive baboons (Papio anubis) behave similarly by avoiding mating with males carrying a symptomatic sexually transmitted bacterial disease (Paciência et al., 2019). Interestingly, these female baboons also avoid mating when they are themselves infected. Guppies (Poecilia reticulata) can use chemical and visual cues to adjust avoidance behavior of infected individuals to times when transmissibility of the parasite is the highest (Stephenson et al., 2018). Social lobsters (Panulirus argus) also avoid groupmates infected with a deadly virus (Behringer et al., 2006). Going back to social insects, when dampwood termites (Zootermopsis angusticollis) produce a vibratory display in the presence of a pathogenic fungus, nestmates distance themselves from the vibrating termites (Rosengaus et al., 1999). While detection of diseased conspecifics or 
disease cues is found in social insects and can directly trigger avoidance (e.g., Lasius niger ant nurses, Stroeymeyt et al., 2018) or aggression (Waddington and Rothenbuhler, 1976; Drum and Rothenbuhler, 1985) in non-infected nestmates, these reactions aren't necessarily always the case (Richard et al., 2008; Leclerc and Detrain, 2016). This may be because, as explained in the previous paragraph, diseased or moribund social insects tend to show spontaneous avoidance of the colony so there is no need to develop discrimination strategies against them, and also because immunity can be socially transferred in some cases (e.g., dampwood termites, Traniello et al., 2002).

In humans, a lot of research on the pathogen avoidance topics described above for other species has been done under a framework referred to as the "behavioral immune system" (Ackerman et al., 2018; Murray et al., 2019). This term describes a system of disease detection that activates behavioral responses aimed at diminishing pathogen exposure. For instance, humans not only recognize visual cues of disease (such as a photograph of a person coughing), but they respond to those cues physiologically by priming their immune system (Schaller et al., 2010). Detection of and preference for health cues also seems to occur in humans. For example, evidence suggests that women prefer the faces and the scent of men heterozygous at Major Histocompatibility Complex (MHC) loci. Heterozygosity at MHC loci has been associated with greater resistance to certain infectious diseases in humans relative to homozygosity (reviewed in Tybur and Gangestad, 2011). Another overlapping term for this disease avoidance behavior is the "disgust adaptive system," a term sometimes used interchangeably with behavioral immune system (Curtis et al., 2011). Disgust here would be the visceral emotional reaction that generally accompanies withdrawal from people (particularly strangers) displaying cues that reliably indicate pathogen presence (Curtis et al., 2004). Although disgust

\section{REFERENCES}

Ackerman, J. M., Hill, S. E., and Murray, D. R. (2018). The behavioral immune system: current concerns and future directions. Soc. Person. Psychol. Compass 12:e12371. doi: $10.1111 / \mathrm{spc} 3.12371$

Behringer, D. C., Butler, M. J., and Shields, J. D. (2006). Avoidance of disease by social lobsters. Nature 441:421. doi: 10.1038/441421a

Bos, N., Lefèvre, T., Jensen, A. B., and D'ettorre, P. (2012). Sick ants become unsociable. J. Evol. Biol. 25, 342-351. doi: 10.1111/j.1420-9101.2011.02425.x

Bouwman, K. M., and Hawley, D. M. (2010). Sickness behaviour acting as an evolutionary trap? Male house finches preferentially feed near diseased conspecifics. Biology Letters 6, 462-465. doi: 10.1098/rsbl.2010.0020

Curtis, V., Aunger, R., and Rabie, T. (2004). Evidence that disgust evolved to protect from risk of disease. Proc. R. Soc. Lond. Series B: Biol. Sci. 271, S131-S133. doi: 10.1098/rsbl.2003.0144

Curtis, V., de Barra, M., and Aunger, R. (2011). Disgust as an adaptive system for disease avoidance behaviour. Philos. Trans. R. Soc. B Biol. Sci. 366, 389-401. doi: 10.1098/rstb.2010.0117

Dantzer, R. (2001). Cytokine-induced sickness behavior: where do we stand? Brain Behav. Immun. 15, 7-24. doi: 10.1006/brbi.2000.0613

Deacon, B., and Olatunji, B. O. (2007). Specificity of disgust sensitivity in the prediction of behavioral avoidance in contamination fear. Behav. Res. Therap 45, 2110-2120. doi: 10.1016/j.brat.2007.03.008

Drum, N. H., and Rothenbuhler, W. C. (1985). Differences in non-stinging aggressive responses of worker honeybees to diseased and healthy bees in May and July. J. Apicult. Res. 24, 184-187. doi: 10.1080/00218839.1985.11100669 is expressed universally in humans, disgust sensitivity is variable across individuals and there are currently no good hypotheses that explain this variation (Tybur et al., 2018). Disgust sensitivity seems to predict the strength of behavioral avoidance of cues of contamination (Deacon and Olatunji, 2007).

Not all disease cues, however, lead to avoidance, particularly if they are relatively novel in a population. One example in which this has been studied is conjunctivitis caused by the bacterial pathogen Mycoplasma gallisepticum. This is a directly transmissible pathogen that causes house finches (Haemorhous mexicanus) to develop visible symptoms around the eye, as well as lethargy. One study found that male house finches preferred to feed near diseased conspecifics, potentially because the diseased animals became less aggressive around food (Bouwman and Hawley, 2010). Such a result raises interesting questions regarding the extent to which animals are able to make appropriate decisions when faced with new circumstances.

Perhaps the important take-home message is that these avoidance behaviors have likely evolved because they increase survival in the presence of disease. Allowing other animals to inspire some of our social rules during this time and to teach us something about community may not be a bad idea. By adopting social distancing as part of our battle against a novel infectious disease, we are fighting against some of what it means to be human: to live socially. But simultaneously, we are also doing a tremendous act of kindness for one another and for our communities.

\section{AUTHOR CONTRIBUTIONS}

The author confirms being the sole contributor of this work and has approved it for publication.

Heinze, J., and Walter, B. (2010). Moribund ants leave their nests to die in social isolation. Curr. Biol. 20, 249-252. doi: 10.1016/j.cub.2009.12.031

Kucharski, A. J., Russell, T. W., Diamond, C., Liu, Y., Edmunds, J., Funk, S., et al. (2020). Early dynamics of transmission and control of COVID19: a mathematical modelling study. Lancet Infect. Dis. 20, 553-558. doi: 10.1016/S1473-3099(20)30144-4

Leclerc, J.-B., and Detrain, C. (2016). Ants detect but do not discriminate diseased workers within their nest. Sci. Nat. 103:70. doi: 10.1007/s00114-0161394-8

Lopes, P. C., Block, P., and König, B. (2016). Infection-induced behavioural changes reduce connectivity and the potential for disease spread in wild mice contact networks. Sci. Rep. 6:31790. doi: 10.1038/srep31790

Lopes, P. C., Block, P., Pontiggia, A., Lindholm, A. K., and König, B. (2018). No evidence for kin protection in the expression of sickness behaviors in house mice. Sci. Rep. 8:16682. doi: 10.1038/s41598-018-35174-0

Müller, C. B., and Schmid-Hempel, P. (1993). Exploitation of cold temperature as defence against parasitoids in bumblebees. Nature 363, 65-67. doi: $10.1038 / 363065 \mathrm{a} 0$

Murray, D. R., Prokosch, M. L., and Airington, Z. (2019). Psychobehavioroimmunology: connecting the behavioral immune system to its physiological foundations. Front. Psychol. 10:200. doi: 10.3389/fpsyg.2019.00200

Paciência, F. M. D., Rushmore, J., Chuma, I. S., Lipende, I. F., Caillaud, D., Knauf, S., et al. (2019). Mating avoidance in female olive baboons (Papio anubis) infected by Treponema pallidum. Sci. Adv. 5:eaaw9724. doi: 10.1126/sciadv.aaw9724 
Poirotte, C., Massol, F., Herbert, A., Willaume, E., Bomo, P. M., Kappeler, P. M., et al. (2017). Mandrills use olfaction to socially avoid parasitized conspecifics. Sci. Adv. 3:e1601721. doi: 10.1126/sciadv.1601721

Richard, F.-J., Aubert, A., and Grozinger, C. (2008). Modulation of social interactions by immune stimulation in honey bee, Apis mellifera, workers. BMC Biol. 6:50. doi: 10.1186/1741-7007-6-50

Rosengaus, R. B., Jordan, C., Lefebvre, M. L., and Traniello, J. F. A. (1999). Pathogen alarm behavior in a termite: a new form of communication in social insects. Naturwissenschaften 86, 544-548. doi: 10.1007/s001140050672

Schaller, M., Miller, G. E., Gervais, W. M., Yager, S., and Chen, E. (2010). Mere visual perception of other people's disease symptoms facilitates a more aggressive immune response. Psychol. Sci, 21, 649-652. doi: $10.1177 / 0956797610368064$

Stephenson, J. F., Perkins, S. E., and Cable, J. (2018). Transmission risk predicts avoidance of infected conspecifics in Trinidadian guppies. J. Anim. Ecol. 87, 1525-1533. doi: 10.1111/1365-2656.12885

Stockmaier, S., Bolnick, D. I., Page, R. A., and Carter, G. G. (2020) Sickness effects on social interactions depend on the type of behaviour and relationship. J. Anim. Ecol.13, 1-8. doi: 10.1111/1365-2656.13193

Stroeymeyt, N., Grasse, A. V., Crespi, A., Mersch, D. P., Cremer, S., and Keller, L. (2018). Social network plasticity decreases disease transmission in a eusocial insect. Science 362, 941-945. doi: 10.1126/science.aat 4793

Traniello, J. F. A., Rosengaus, R. B., and Savoie, K. (2002). The development of immunity in a social insect: evidence for the group facilitation of disease resistance. Proc. Natl. Acad. Sci. U.S.A. 99, 6838-6842. doi: 10.1073/pnas.102176599

Tybur, J. M., Çinar, Ç., Karinen, A. K., and Perone, P. (2018). Why do people vary in disgust? Philos. Trans. R. Soc. B 373:20170204. doi: 10.1098/rstb.2017.0204

Tybur, J. M., and Gangestad, S. W. (2011). Mate preferences and infectious disease: theoretical considerations and evidence in humans. Philos. Trans. R. Soc. B Biol. Sci. 366, 3375-3388. doi: 10.1098/rstb.2011.0136

Waddington, K. D., and Rothenbuhler, W. C. (1976). Behaviour associated with hairless-black syndrome of adult honeybees. J. Apicult. Res. 15, 35-41. doi: 10.1080/00218839.1976.11099831

WHO (2020). Coronavirus Disease 2019 (COVID-19). Situation report 46 Available online at: https:/www.who.int/docs/default-source/coronaviruse/ situation-reports/20200306- sitrep-46-covid-19.pdf?sfvrsn=96b04adf_4 (March 6, 2020).

Conflict of Interest: The author declares that the research was conducted in the absence of any commercial or financial relationships that could be construed as a potential conflict of interest.

Copyright (c) 2020 Lopes. This is an open-access article distributed under the terms of the Creative Commons Attribution License (CC BY). The use, distribution or reproduction in other forums is permitted, provided the original author(s) and the copyright owner(s) are credited and that the original publication in this journal is cited, in accordance with accepted academic practice. No use, distribution or reproduction is permitted which does not comply with these terms. 